\title{
Predoctoral Teaching in Intravenous Conscious Sedation: Ten Years at Glasgow Dental School
}

\author{
Nigel D. Robb, T.D., Ph.D., B.D.S., F.D.S.R.C.S.Ed., F.D.S. (Rest Dent), F.D.S.R.C.P.S., \\ F.H.E.A.; Jason Leitch, B.D.S., F.D.S.R.C.S. (Eng.), F.D.S.R.C.S.Ed., F.D.S.R.C.P.S., \\ D.D.S., M.P.H.; Conor O'Brian, B.D.S., F.D.S.R.C.S. (Eng.); Peter Walker, B.D.S., \\ M.F.D.S.R.C.S.Ed., M.Sc. (Dent Sci)
}

Abstract: Supervised clinical practice in intravenous conscious sedation was introduced into the predoctoral dental curriculum at Glasgow Dental School and Hospital, United Kingdom, with the appointment of two full-time academic staff members in 2001. This article reviews the student experience gained in the succeeding ten years. All students administered intravenous sedation to patients during the course as well as assisting with intravenous sedation provided by their peers. The experience was variable, mainly as a result of student and patient attendance. Adverse weather and increasing student numbers also affected student experience. This study demonstrated that it is possible to provide supervised clinical sedation practice for students as part of a predoctoral dental curriculum.

Dr. Robb is Reader in Restorative Dentistry, School of Oral and Dental Sciences, University of Bristol, United Kingdom; Dr. Leitch is Clinical Director, Quality Unit, Scottish Government Health and Social Care Directorate, Edinburgh, United Kingdom; Dr. O'Brian is Associate Specialist in Oral Surgery, Glasgow Dental Hospital and School, Glasgow, United Kingdom; and Dr. Walker is Senior Dental Officer (Sedation), NHS Greater Glasgow and Clyde, Glasgow, United Kingdom. Direct correspondence and requests for reprints to Dr. Nigel D. Robb, School of Oral and Dental Sciences, University of Bristol, Lower Maudlin Street, Bristol BS1 2LY, United Kingdom; 44-117-342-4144 phone; nigel.robb@bristol.ac.uk.

Keywords: dental education, clinical education, intravenous sedation, United Kingdom

Submitted for publication 1/19/12; accepted 4/6/12

$\mathrm{T}$ The teaching of conscious sedation at the predoctoral level has been a variable experience for generations of dental students around the world. At some schools, the teaching has been excellent, and students have had the opportunity to manage patients under intravenous sedation for many years although discrepancies have been found..$^{1,2}$ Over a decade ago, Glasgow Dental School and Hospital, United Kingdom, perceived that there was a problem with the delivery of predoctoral education in conscious sedation and, in 2001, appointed a senior lecturer and a lecturer in sedation. Four dental nurses were also appointed as part of the team, and a two-surgery dedicated Sedation Suite was developed to house the clinical activity. These developments resulted in an expansion of sedation teaching from observational experience for the students to one in which they undertook treatment working in pairs.

The aim of the course was to comply with the General Dental Council (GDC) recommendations that dental undergraduates in the United Kingdom should "have had practical experience of administering inhalation and intravenous sedation and of operating on sedated patients." ${ }^{3}$ The sedation course ran for the first time during the academic year 200102. Prior to supervised clinical practice, a series of lectures was introduced in the pre-2004 course as part of the fourth-year therapeutics course. The lectures were planned to cover the didactic syllabus as published by the Dental Sedation Teachers' Group. ${ }^{4}$ The lectures given are listed in Table 1. The teaching was examined as part of the fourth-year professional examination prior to the commencement of supervised clinical practice during the final (fifth) year.

The students attended the clinic in groups of four, and each was scheduled to attend seven sessions. The first session was an introduction to the Sedation Suite. The activities covered are shown in Table 2. The introductory sessions were held for approximately one-fifth of the year at a time at the start of the academic year. When the students attended, they worked in pairs: one acting as the operator/ sedationist whilst the second assisted. Each pair of students had a sedation-trained dental nurse present in the surgery throughout patient treatment, and the two surgeries were supervised by one of the two members of the academic staff appointed to teach sedation. Each pair of students had three patients 
booked at one-hour intervals, with a fifteen-minute staggered start time. This allowed the academic staff member present to supervise intravenous cannulation and the start of titration of sedative drugs prior to moving to the other pair.

The B.D.S. curriculum was completely restructured in 2004 and was implemented for the first time during the academic year 2004-05. One of the major changes in the structure was the use of outreach teaching for adult dental care, which resulted in the final-year students spending 50 percent of the year out with the Dental Hospital and School. Since it was anticipated that during outreach the students would be able to gain some sedation experience, it was decided that the in-house clinical sedation teaching should be brought forward to the fourth year. The didactic component was brought forward to the last month of the third year. The structure of the sedation course was changed from a series of lectures to a symposium format occupying five morning sessions in a single week (Table 3 ). The same information was covered as in the pre-2004 curriculum, but the increased amount of small-group teaching facilitated a more discussion-based method of instruction.

The timing of the sedation symposium meant that it fell after the Year 3 professional examination. It was felt desirable to maintain an academic assessment of the students' knowledge prior to commencing supervised clinical practice during the fourth year. The main summative assessment would be as part of the written final examinations at the end of the fourth year, but this would be after completion of the supervised clinical practice. Thus, a multiple-choice question assessment was included at the end of the symposium. Students who failed to reach the required standard were invited for an exam and given further reading to carry out prior to treating patients.

The number of sessions of supervised clinical practice was maintained except during the academic year 2010-11 when, as a result of the large number of students in the class, the number of sessions was reduced by one per student. In the new curriculum, the students also attended one sedation assessment clinic in an observational capacity. During the students' supervised clinical practice, their activity was logged using Dental Sedation Teachers' Group (DSTG) $\log$ sheets as published in the DSTG guidance. ${ }^{4}$ On completion of their clinical attachment, the students kept their copy of the student log sheet, and the staff copy was retained in the Sedation Suite. During the transition from the pre-2004 to 2004 curricula, one year of students undertook their supervised clinical
Table 1. Sedation lectures in the pre-2004 dental curriculum at the University of Glasgow

1. Introduction Role of sedation and anxiety control

2. Assessment and treatment planning Patient assessment, relevance of medical history, anxiety history, social history, consent

3. Pharmacology of sedative agents Benzodiaepines and nitrous oxide: effects, side effects, mechanisms of action

4. Inhalational sedation Historical review and rationale, nitrous oxide pharmacology, Quantiflex machine, indications and contra-indications, practical techniques, pollution

5. Intravenous sedation 1 History, pharmacology of benzodiazepines, cannulation, practical technique, indications and contraindications, monitoring, emergencies, Flumazenil, new techniques

6. Intravenous sedation 2 As above

7. Alternatives Oral, transmucosal, roles, and technique

8. Monitoring The use of clinical and electronic monitoring in sedation, including pulse oximetry and non-invasive blood pressure

9. Medico-legal issues Current guidance on practice of sedation, General Dental Council regulations, and expert working groups

10. Complications of sedation Respiratory and other complications

\section{Table 2. Introduction to Sedation Suite}

1. Tour of Sedation Suite Introduction to staff Fire alarm protocols

2. Intravenous cannulation Practice on mannequin Practice on colleagues

3. Patient journey through IV sedation treatment Drawing up of drugs Titration of sedative Patient monitoring

4. Documentation

5. Inhalation sedation Equipment demonstration Trial administration on colleagues

practice within the Community Dental Service. Results were not available for that year.

The aim of the study reported here was to quantify the experience gained by dental students in the clinical provision of intravenous conscious sedation with midazolam in Glasgow Dental Hospital and 
Table 3. B.D.S. 2004 sedation symposium

\begin{tabular}{|c|c|c|c|c|}
\hline Introduction to pain and & Psychological aspects & Assessment for & 0900-1030: & 0900-1030: \\
\hline ar & $\mathrm{O}$ & ation & A: Practical skill & C: Practical skill \\
\hline Applied biomedical & Demonstration of & Inhalational sedation & stations & stations \\
\hline $\begin{array}{l}\text { science respiratory } \\
\text { system }\end{array}$ & $\begin{array}{l}\text { relaxatıon techniques } \\
\pm \text { nitrous oxide }\end{array}$ & Intravenous sedation & $\begin{array}{l}\text { B: Alternatives/medico- } \\
\text { legal/complications }\end{array}$ & $\begin{array}{l}\text { D: Alternatives/medico- } \\
\text { legal/complications }\end{array}$ \\
\hline Cardiovascular system & & & & \\
\hline Pharmacology & & & 1100-12.30 & 1100-12.30 \\
\hline & & & $\begin{array}{l}\text { B: Practical skill } \\
\text { stations }\end{array}$ & $\begin{array}{l}\text { D: Practical skill } \\
\text { stations }\end{array}$ \\
\hline & & & $\begin{array}{l}\text { A: alternatives/medico- } \\
\text { legal/complications }\end{array}$ & $\begin{array}{l}\text { C: Alternatives/medico- } \\
\text { legal/complications }\end{array}$ \\
\hline & & & $\begin{array}{c}\text { C, D: Case study and } \\
\text { self-instruction }\end{array}$ & $\begin{array}{c}\text { A, B: Case study and } \\
\text { self-instruction }\end{array}$ \\
\hline
\end{tabular}

School between 2001 and 2011. The objectives of the study were 1) to confirm the impression that all students were completing their course with a level of experience that complied with the contemporary General Dental Council guidance and 2) to identify any factors recorded on the student log sheets that could explain a variation in the experience gained.

\section{Methods}

The experience of students in intravenous sedation was entered from the clinical log sheets into a spreadsheet program. The activity was classified according to the students' involvement in patient management. The roles and descriptions of the roles are listed in Table 4. For the purposes of this article, which aims to document the students' experience, the first two categories have been combined to represent the number of times the students administered sedation. The results are presented for the years for which logs were available. Approval for publication was sought from the Head of School. As there were no human subjects involved, ethical approval was deemed not to be required.

\section{Results}

The number of cases seen is shown in Table 5 for the pre-2004 curriculum and Table 6 for the 2004 curriculum. The results for the pre-2004 curriculum show that there was a gradual increase in students' experience as the course developed. The slow start reflected the fact that the two academic staff members took their positions shortly before the first year of students started their course; thus, there was a delay in recruiting enough patients to provide thirty patients per week. Students in the years with larger numbers of students tended to have less experience than in other years although there was a large variation in the experience of individual students.

\section{Discussion}

A number of factors influenced the results and confounded the staff members' attempts to balance the students' experience. The evidence is based on the day-by-day experience of the supervising clinical and dental nursing staff members. The issues were raised at a hospital/school level and, whilst not directly extrapolated from the data, are included here as they are useful factors to consider for those developing similar teaching programs.

The timetable was such that the students attended sedation between the penultimate week in September and the first full week of May. In years with larger numbers of students, the fixed time available meant that the number of sessions had to be reduced when student numbers rose. During the academic year 2010-11, there were some groups that contained five students rather than four. This resulted in one student being allocated study time per sedation session. The range of number of patients seen partly reflects the chance element of clinical teaching in that experience depends on patients attending. One factor that had a significant impact on patient (and student) attendance was the adverse weather during the winter. During the first week of December, for example, there was virtually no clinical activity.

Changes in the system for making appointments resulted in staff members' failing to use all available clinical slots because they were unfamiliar 
Table 4. Dental student involvement in intravenous conscious sedation

Role Clinical Activity

Operator/Sedationist

Student administers sedation and carries out sedation

Sedationist*

Student administers sedation; member of staff to carry out treatment

Assistant

Student assists with the sedation \pm the dental treatment

Observer

Student observes treatment without being actively involved

*This role was only undertaken if the dental treatment was beyond the scope of the students. The teaching was that the operator/ sedationist role was the norm, and thus students did not sedate patients for their peers to treat.

Table 5. Intravenous sedation experience of dental students in the pre-2004 curriculum

\begin{tabular}{lccc} 
Academic Year & Number of Students & $\begin{array}{c}\text { Mean Number of } \\
\text { Administrations of IV Sedation } \\
\text { (Standard Deviation, Range) }\end{array}$ & $\begin{array}{c}\text { Mean Number of } \\
\text { Cases of IV Sedation Assisting } \\
\text { (Standard Deviation, Range) }\end{array}$ \\
\hline $2001-02$ & 78 & $2.4(1.0,1-6)$ & $2.2(1.0,1-5)$ \\
$2002-03$ & 64 & $4.0(1.3,1-8)$ & $3.0(1.5,1-8)$ \\
$2003-04$ & 68 & $4.8(1.3,1-8)$ & $4.3(1.4,2-7)$ \\
$2004-05$ & 64 & $5.4(1.7,2-10)$ & $4.7(1.7,2-8)$ \\
$2005-06$ & 81 & $4.3(1.5,1-7)$ & $4.0(1.5,2-8)$ \\
$2006-07$ & 70 & $5.2(2.1,1-10)$ & $3.8(1.8,1-8)$ \\
$2007-08$ & 62 & $5.4(0.9,4-7)$ & $4.7(1.4,3-7)$ \\
\hline
\end{tabular}

Table 6. Intravenous sedation experience of dental students in the 2004 curriculum

\begin{tabular}{lccc} 
Academic Year & Number of Students & $\begin{array}{c}\text { Mean Number of } \\
\text { Administrations of IV Sedation } \\
\text { (Standard Deviation, Range) }\end{array}$ & $\begin{array}{c}\text { Mean Number of } \\
\text { Cases of IV Sedation Assisting } \\
\text { (Standard Deviation, Range) }\end{array}$ \\
\hline $2008-09$ & 60 & $4.7(1.5,1-7)$ & $4.2(1.5,1-7)$ \\
$2009-10$ & 77 & $4.4(1.4,2-8)$ & $4.2(1.5,1-8)$ \\
$2010-11$ & 85 & $3.2(1.2,1-6)$ & $2.8(1.2,2-7)$
\end{tabular}

with the set-up of clinics in the Sedation Suite. One surgery was consistently left either underfilled or completely empty. Patients who require sedation are inevitably more anxious regarding attendance and thus tend to have a higher failure to attend rate. Furthermore, the requirement for having a responsible adult to act as an escort for the patient means that there are two individuals who have to be in good health and able to get time off work to attend. Thus, the cancellation rate for these patients can be higher, particularly at times when there is a high incidence of infectious diseases.

Student attendance at clinical sessions can also be an issue. In a small but significant number of cases, students missed a significant proportion of their clinical time due to illness. Although attendance is monitored, there was no system or indeed flexibility in the system to compensate for this other than if the student were required to repeat a year's study.
Interestingly, participation in this course uncovered a number of students who had significant needle phobia. Three students were unable to cannulate patients at the start of their course due to needle phobia. All were referred to the University Health Service for psychological therapy after which they were able to attend and treat patients.

According to feedback gathered in end-of-year questionnaires, the students rated the course very highly, particularly the close support from the dental nurses and the experience in caries management. A total of 2,969 patients were treated by dental students within the Sedation Suite within the reported period. Whilst there was no central recording of a clinical outcome, no patients were reversed with flumazenil as a result of being oversedated, and no formal complaints were received regarding treatment provided by students. 
In the requirements for competence in intravenous sedation defined by the Dental Sedation Teachers' Group, ${ }^{5}$ the recommendation is that most individuals will require twenty supervised cases prior to being prepared for independent practice. The intention of this course was to fulfil the GDC's requirement that the graduate have "a knowledge" of sedation: that is, that they had not received only didactic teaching but also gained clinical experience in both using intravenous sedation and treating patients who were sedated.

\section{Conclusions}

The establishment of our teaching program in conscious sedation achieved its objectives in providing all of the students with "a knowledge" of conscious sedation as required by the GDC. It is possible to provide predoctoral students with training in conscious sedation, provided that it is adequately resourced and supported. All of the students gained experience in both sedating and assisting with the sedation of patients treated under intravenous conscious sedation.

As a result of this study, we can make several recommendations for programs of this type. First, systems should be put in place to maximize patient attendance at educational sessions to ensure adequate and consistent exposure for dental students. These might include confirmation of appointments by text message or phone call and ensuring all reception staff have an adequate understanding of the way all clinics run. Second, a system should be developed to allow for remedial sessions for students who have received less experience prior to progression. This is needed because there are logistical difficulties with already congested curricula. Third, all student clinical activity should be centrally collated to allow appropriate monitoring of clinical experience and ensure that variations in experience are identified early whilst there is time to arrange remediation. Fourth, clear guidance on what is within the dentist's scope of practice should be made available prior to admission so that individuals who have potential issues can act to address them prior to having an impact on the educational process. Finally, the implications of increasing student intakes or changing curricula such that there is an increased demand on clinical teaching facilities must be planned to ensure that any reduction in clinical experience is anticipated and a plan developed to manage the change.

\section{REFERENCES}

1. Leitch JA, Girdler NM. A survey of the teaching of conscious sedation in dental schools of the United Kingdom and Ireland. Br Dent J 2000;188(4):211-6.

2. Leitch JA, Jauhar S. A follow-up survey of the teaching of conscious sedation in dental schools of the United Kingdom and Ireland. Am Dent Society Anaesthesiol 2006;53:43-8.

3. The first five years: the undergraduate dental curriculum. London: General Dental Council, 1997.

4. Dental Sedation Teachers Group. Sedation in dentistry: undergraduate training, guidelines for teachers, 2002. At: www.dstg.co.uk/teaching/ugrad-teaching. Accessed: December 11, 2011.

5. Dental Sedation Teachers Group. Training in conscious sedation for dentistry, 2005. At: www.dstg.co.uk/documents. Accessed: January 12, 2012. 